\title{
Erratum to: Hiatal Hernia Surgery
}

\author{
Muhammed Ashraf Memon
}

\section{Erratum to:}

M.A. Memon, Hiatal Hernia Surgery, An Evidence Based Approach, DOI 10.1007/978-3-319-64003-7

In the original version of the book, the first name of the editor was incorrectly spelled as Muhammad Ashraf Memon in the Cover and Front matter.

The correct version of the editor name is Muhammed Ashraf Memon.

The online version of the original book can be found under DOI 10.1007/978-3-319-64003-7

\footnotetext{
M.A. Memon

Faculty of Health Sciences and Medicine, Department of Surgery,

University of Queensland Mayne Medical School, Brisbane, Queensland, Australia 